\title{
UM ESTUDO DO TERMO “CERÂMICA ICOARACIENSE"1
}

\section{A STUDY OF THE TERM "CERÂMICA ICOARACIENSE"}

\author{
Elizabeth Conde de MORAIS*
}

\begin{abstract}
RESUMO: Esta reflexão objetiva delimitar conceitos relacionados ao termo Cerâmica Icoaraciense, partindo de concepções que demonstram que o léxico de uma língua é suscetível a mudanças com a inovação de palavras, do mesmo modo que o termo se renova para expressar a prática cultural realizada pela comunidade. Esta análise utiliza os estudos bibliográficos a partir de leituras que tratam sobre a Terminologia, tendo como referência Faulstich (1998), Krieger e Finatto (2004) e Lara (1999), para os quais importa a instituição do sentido do novo termo; de textos científicos que tem como ponto central pesquisas sobre a cerâmica criada em Icoaraci. Esta abordagem, de caráter interdisciplinar, apoia-se na constituição do termo em textos nas áreas da antropologia e das ciências sociais. Para referendar a constituição discursiva do termo com a relação de identidade adotou-se a análise de Maingueneau (2008), visto que a apropriação dessa nova forma de expressão é uma apropriação para justificar a identidade cultural com o seu locus de criação.
\end{abstract}

Palavras-chave: Cerâmica Icoaraciense. Terminologia. Identidade.

\begin{abstract}
This objective reflection define concepts related to the term Cerâmica Icoaraciense, from conception to show that the lexicon of a language is susceptible to change, with the innovation of words, just as the term is renewed to express the cultural practice carried out by the community. This analysis uses the readings from bibliographic studies dealing on Terminology, with reference Faulstich (1998), Krieger e Finatto (2004) and Lara (1999), for which matter the institution of the meaning of the new term; texts scientific whose midpoint surveys pottery created in Icoaraci. This approach, interdisciplinary, relies on the constitution of term texts in the fields of anthropology and the social sciences. To endorse the discursive constitution of the term with the identity relation adopted the analysis Maingueneau (2008), since the appropriation of this new form of expression is an appropriation to justify cultural identity with their locus of creation.
\end{abstract}

Keywords: Cerâmica Icoaraciense. Terminology. Identity.

\section{Introdução}

A linguística é uma área de estudo que possibilita ampliar a visão sobre a linguagem nas práticas cotidianas. Dentre os diversos ramos que constituem os estudos da língua a terminologia é a ciência que permite fazer um recorte em uma prática cultural presente em um determinado contexto, ao mesmo tempo em que admite validar os léxicos presentes no ato de comunicação a partir da análise dos termos relacionado a uma manifestação cultural. Diante

\footnotetext{
* Mestranda do Programa de Pós- Graduação em Linguagem e Saberes na Amazônia, UFPA- Campus Bragança, e-mail: elibethconde@gmail.com.
} 
dessa acepção este estudo tem como objetivo refletir sobre o sintagma terminológico Cerâmica

\section{Icoaraciense.}

Para melhor situar sobre o centro de atenção dessa análise, torna-se pertinente destacar que esta investigação faz parte da constituição da pesquisa "As representações simbólicas da cerâmica Icoaraciense", vinculada ao curso de Pós-Graduação Linguagens e Saberes na Amazônia, da Universidade Federal do Pará - Campus de Bragança, a pesquisa parte da etnografia e é desenvolvida em lócus nas lojas e olarias em Icoaraci, tem como objetivo fazer um recorte nas falas das pessoas fonte, os artesãos, investigando as concepções ideológicas presentes nos discursos assumidos ao longo da narrativa. Contudo, o estudo aqui proposto tem o seu foco em textos de outros pesquisadores que se debruçaram sobre o tema anteriormente.

É importante situar o espaço no qual a "Cerâmica Icoaraciense" se desenvolve hoje. Na cidade de Belém há um espaço denominado Distrito Industrial de Icoaraci, nesse lugar há a produção da cerâmica a partir da matéria-prima argila. Nessa fábrica, ou olaria, como denominam as pessoas da comunidade, as peças são confeccionadas desde o período da colonização - atividade que ganha maior vigor na metade do século XX. É interessante ressaltar que as peças, antes de cunho unicamente utilitário, confeccionadas de forma simples para atender à demanda domiciliar, hoje, com o passar do tempo, sofreram modificação quanto ao tipo de cerâmica criada em Icoaraci, fruto do processo histórico. O artesanato se desmembrou também em cerâmica arqueológica e decorativa. Tem-se assim uma prática que merece destaque no espaço Amazônico, pois faz referência a esse lugar - Icoaraci - porquanto marca de representação o termo "Cerâmica Icoaraciense", que assumiu uma identidade, ou seja, a utilização do vocábulo remete automaticamente à prática cultural.

É importante observar que se quer apresentar o sentido do termo no discurso, cabendo refletir como o sujeito possivelmente representa o seu lócus e faz instituir sentido a partir da criação de novos vocábulos para representar uma ação que o caracteriza. "O sentido não é apenas a contraparte do significante; ele é um efeito do aparecimento do significante em condições dadas" (POSSENTI, 2002, p. 172). Compreende-se que o significado é fruto da influência sofrida durante o processo histórico, de constituição do lugar. Ao formar a sua identidade, que hoje é considerada peculiar, ímpar e representativa do ambiente, faz entender que aquela referência em algum momento o contagiou, fazendo o indivíduo assumir para si esse identificador.

O termo ora abordado faz parte de uma realidade presente na vida das pessoas que vivem naquele espaço e, como tal, as pronúncias dessas duas palavras que antes eram cerâmica e Icoaraci, agora gera um sentido único no contexto de quem o usa. O sentido constituído por ele tem uma representação para o usuário ao validar o discurso assumido pelas pessoas que dele usufruem como forma de indicar a prática cultural, o que possibilita gerar uma identificação atrelada ao lugar onde a cerâmica é criada, neste caso em Icoaraci. 
É interessante citar que as ponderações referendadas partem da área da terminologia, contudo apoiam-se em outras áreas do conhecimento como na antropologia e nas artes, enquanto forma de embasar a constituição desse objeto de estudo. O aporte teórico utilizado é justificado pelo fato de a análise necessitar ancorar-se nas outras ciências, visto que a prática cultural, ora citada, está envolta em um contexto complexo, numa relação dinâmica nesse dado espaço social. Assim, faz parte dos estudos terminológicos indicar o modo como os termos são utilizados pelos falantes que dela fazem uso. A validade desse estudo assume uma representatividade e para compreender esse fenômeno para elencar a observação, o tipo e as fases da análise são delimitados no próximo tópico.

\section{Procedimentos Metodológicos}

A utilização do termo pelos usuários favorece que o demarquem como representação da ação cultural e, assim, gera identidade. A investigação busca averiguar a ocorrência deste vocábulo com base na análise bibliográfica que "trata-se da pesquisa desenvolvida a partir das referências teóricas que apareceram nos livros, artigos documentos, etc." (MICHALISZYN, 2008, p. 51). É interessante ressaltar que a análise tem como base os estudos da terminologia, a partir das leituras teóricas que favorecem o entendimento para a constituição do termo "Cerâmica Icoaraciense" em vista do estabelecimento do seu sentido.

O exame do comportamento das unidades terminológicas em seu real contexto de ocorrência, compreendendo que as unidades aparecem de maneira natural no discurso, não constituindo uma língua à parte, como inicialmente se julgava. Consequentemente, os termos sofrem os efeitos de todos os mecanismos sintagmáticos e pragmáticos das cadeias discursivas que dão suporte à comunicação especializada. (KRIEGER; FINATTO, 2004, p. 106-107).

As unidades terminológicas são entendidas como expressões que delimitam um contexto específico e, com isso, estão envoltas em sentidos próprios e representativos para seus usuários. Esse entendimento possibilita a utilização do aporte teórico para legitimar a análise do estudo de especialidade proposto.

Na fase de análise são utilizadas também as leituras de textos científicos, nos quais os autores usam como instrumento de investigação a pesquisa de campo, que têm como objeto de estudo a "Cerâmica Icoaraciense" e, portanto, apresentam nos textos o tema da pesquisa: As representações simbólicas da cerâmica Icoaraciense. Cabe então nesse momento citar o título dos trabalhos científicos: A etnomatemática da ornamentação da cerâmica icoaraciense praticada no Liceu do Paracuri. (FERRETE, 2005); O trabalho dos artesãos ceramistas em Icoaraci, Belém/PA: contribuições aos estudos sobre a dinâmica da Amazônia brasileira. (SOUZA, 2010); Fazendo Arte: a relação entre o valor simbólico e o valor utilitário da cerâmica no Distrito de Icoaraci/PA. (XAVIER, 2001).

A utilização destes textos tem validade nos estudos da linguagem, ao disponibilizar 
leituras sobre o vocábulo ora analisado. "O contexto discursivo, é também responsável por uma aproximação entre os estudos terminológicos e os que, independente de particularidades e interesses específicos, tornam o texto como objeto central da análise." (KRIEGER; FINATTO, 2004, p. 107). No plano do desenvolvimento da análise, em busca da constituição do entendimento sobre o termo, o recorte durante a etapa é feito a partir de trechos do texto escrito, que fazem citação do objeto, a utilização do recurso demarca que o vocábulo tem legitimidade neste plano contextual.

A interface entre os referências indicados que tem como tema a "Cerâmica Icoaraciense" e as leituras sobre terminologia validam a discussão proposta na atividade, pois a utilização de ambas é fundamental para a construção do entendimento no processo de análise do termo.

É interessante apontar que no plano dos estudos da linguagem o ser humano organiza as suas relações de acordo com a sua necessidade e a língua é um recurso que disponibiliza o processo de interação das pessoas dentro no plano do espaço social. O surgimento de novos vocábulos é necessário no processo de formação socio-histórico do lugar para entender a validade da recorrência do termo no cotidiano do espaço social. Este fator justifica a importância dos estudos de especialidade, em vista de abalizar a constituição do termo como referência, ponto de discussão seguinte.

\section{Da fundamentação teórica à problematização: uma questão terminológica}

A terminologia no plano dos estudos dos termos de especialidade possibilita reconhecer o uso das palavras de uma dada conjuntura e o seu valor ímpar. A forma de expressão passa a identificar a situação de forma peculiar, caracterizando-a como termo que posteriormente necessita do aporte teórico da terminologia para validar a investigação, como a instituição do sintagma terminológico "Cerâmica Icoaraciense".

A partir do entendimento sobre a importância do objeto de estudo, a análise realizada traça a questão problema e delimita o seguinte questionamento: qual a representatividade do sintagma terminológico "Cerâmica Icoaraciense"? O vocábulo é utilizado para determinar uma prática cultural no contexto amazônico, a partir da confecção de peças em cerâmica utilitária, decorativa e arqueológica, presente nos discursos dos artesãos, as pessoas que criam as peças, e dos consumidores, moradores do distrito e turistas que frequentam a localidade, ao reconhecerem Icoaraci como referência na produção desse objeto. E, em consequência, é refletida a utilização do termo em textos que fazem estudos sobre a prática cultural.

O contexto de uso do termo cria possibilidade de sentido peculiar, pois os "termos são signos que encontram sua funcionalidade nas linguagens de especialidade, de acordo com a dinâmica das línguas: são entidades variantes, porque fazem parte de situações comunicativas distintas" (FAULSTICH, 1998, p. 62), as elocuções passam a ser constituídas dentro de um 
espaço e, com isso, demandam destaque para melhor se compreender a sua constituição no plano de estudos da ciência dos termos.

Importa também delinear que o objeto desse estudo é um sintagma terminológico definido como "as unidades complexas, também denominadas de sintagmas terminológicos, são predominante nas comunicações especializadas.” (KRIEGER; FINATTO, 2004, p. 81). Essa ocorrência deve-se ao fato de que um nome só não cria sentido, ao ser usado de forma isolada, sendo assim, a construção terminológica necessita ser reconhecida no seu todo, para assim criar sentido, e configurar uma identidade própria no espaço social do qual faz parte.

La creación de términos especializados no es entonces muy diferente de la formación de los vocablos: (...) el vocablo se forma en el interior de la comunidad linguística como efecto de la división social del trabajo, y como resultado de intereses históricos de la comunidad, por lo que está siempre definido en un contexto cultural. (LARA, 1999, p. 53).

Compreender de que forma esse termo se constitui favorecerá apontar que possivelmente faz parte de um processo histórico de apropriação, em vista desse uso criar a possibilidade de reconhecimento da prática cultural, pois os vocábulos são criados a partir da necessidade da comunidade que a utiliza. Entendimento que será constituído no próximo tópico dessa análise.

\section{A constituição do termo Cerâmica Icoaraciense}

Esse estudo, enquanto parte do plano da linguística especificamente com foco na terminologia, apoia-se nas áreas da antropologia e das ciências sociais. A base dos estudos terminológicos nessas leituras é pertinente para expor a constituição do termo: "Cerâmica Icoaraciense", havendo a necessidade de o estudo assentar-se em textos que assumem essa discussão. "Para o reconhecimento de uma terminologia, é também relevante a consideração pelos propósitos maiores que presidem a comunicação especializada, concretizada em textos de tipologias e pertencentes a distintos universos de discursos" (KRIEGER; FINATTO 2004, p. 57), conhecer as leituras que utilizam o objeto de estudo como foco da sua investigação é pertinente para compreender o sentido do termo, visto que são frutos de pesquisas que já passaram por aprovação no ambiente acadêmico. Com o intuito de ampliar o presente referencial, esse tópico visa fazer um estudo sobre o sintagma terminológico, apoiado nos textos de análise científica sobre a cerâmica de Ferrete (2004, 2005); Souza (2010) e Xavier (2001).

Importa nessa fase do texto instituir o sentido do termo estudado, como mencionado, em um sintagma terminológico, fruto da relação de sentido de duas palavras e, assim, apresentados os significados de ambos, sempre com a visão que possuem um sentido único para essa reflexão, ação necessária para demonstrar a validade do estudo do sintagma terminológico na investigação.

Portanto, a presente análise inicia com a descrição do substantivo 'cerâmica'. Segundo 
o dicionário eletrônico Houaiss da Língua Portuguesa (2006) cerâmica é a "arte e técnica da fabricação de objetos tendo a argila como matéria-prima", logo, a produção do objeto investigado parte de uma matéria-prima, que a partir da sua modificação cria forma e, com isso, é interessante citar que a cerâmica produzida em Icoaraci possui uma representatividade própria.

\begin{abstract}
A produção da cerâmica icoaraciense segue as linhas decorativa e utilitária e nas peças, predomina o estilo que consiste na junção de vários outros estilos, principalmente o estilo marajoara e tapajônico, com a utilização mais expressiva das técnicas de incisão e excisão caracterizada pelos grafismos externos. (FERRETE, 2005, p. 83).
\end{abstract}

A caracterização do objeto estudado merece destaque ao apontar como ela é vista pelo pesquisador como o termo "Cerâmica Icoaraciense" e assume uma feição, com a descrição da confluência de vários estilos à ação que gera sentido. A acepção possibilita dizer que a peça em cerâmica tem uma identidade singular, dinamização pelo processo socio-histórico, instituída como uma representação de uma prática amazônica. A partir dessa percepção, a palavra antes 'cerâmica' se junta à outra 'Icoaraci', que por sua vez assume, na sua forma derivacional, ao acrescentar o sufixo -ense, a forma de demarcar que a criação do artesanato possui referência, com o lugar de origem.

Cria-se uma relação de identidade com o seu lócus de concepção para demarcar esse entendimento da cerâmica que gera o termo que a caracteriza. A inovação é justificada pelo fato da língua estar passível a modificações e, como tal, o seu usuário a molda de acordo a necessidade. "As regras de formação têm seu lugar não na mentalidade ou na consciência dos indivíduos, mas no próprio discurso; elas se impõem, por conseguinte, segundo uma espécie de anonimato uniforme, a todos os indivíduos que tentam falar nesse campo discursivo." (FOUCAULT apud MAINGUENEAU, 2008, p. 52). O entendimento da criação do termo no plano do discurso pode ser visto como um fenômeno, fruto da relação dos sujeitos com espaço social e tem a necessidade de identificar a prática cultural, com a utilização do termo. Sendo assim, a relação do objeto com o seu lugar de origem assume uma identificação própria.

Desse modo, busca-se compreender Icoaraciense, antecipando-se que faz alusão ao morador do distrito de Icoaraci. O nome atribuído a esse lugar "em tupi-guarani significa de frente para o sol" (AVIZ, 2006, p. 139), faz referência a um fenômeno natural, visto que o sol se põe para o espaço considerado a frente do distrito, a primeira rua: Siqueira Mendes, no qual tem a orla um dos pontos turísticos do lugar.

Contudo, há necessidade de registrar que esse lugar denominado Icoaraci é um distrito industrial do município de Belém, estado do Pará, por isso apresenta características expressivas:

O Distrito de Icoaraci é constituído por vários bairros e conjuntos habitacionais. Conta com atividades industriais, portuárias e comerciais, desenvolvidas principalmente por estaleiros, indústrias de beneficiamento de couro, indústrias de pesca, cervejarias, madeireiras, serrarias, pequenas olarias onde se fabricam tijolos e telhas, além do artesanato (principalmente a cerâmica) e estabelecimentos comerciais com fins lucrativos (bares, restaurantes e clubes) (AVIZ, 2006, p. 139). 
O lugar possui uma representatividade no contexto da capital do Pará, ao ter no seu interior empresas, as quais geram renda considerável. Para compreender melhor esse cenário traça-se um breve histórico, ao longo do processo de ocupação da Amazônia. O distrito era ocupado inicialmente pelas tribos indígenas; quando da fundação da cidade de Belém, este lugar foi cogitado para a instalação do forte do Castelo, projeto abandonado devido às características geográficas desfavoráveis, pois é cortada por furos e suscetível à invasão. Com o passar do tempo, foi dividida em duas fazendas e, posteriormente, tornou-se um ambiente com atribuições próprias e com potencial econômico, principalmente pelas suas características geográficas, visto a facilidade de acesso por via marítima, pois é banhada pela Baía do Guajará e pelo Rio Maguari, rotas de transporte da região.

Acrescentando também que o distrito é o polo produtor da cerâmica em argila, desde a época da colonização dentro de um processo histórico de ocupação da Amazônia.

O surgimento do trabalho artesanal em Icoaraci está associado à instalação da missão religiosa dos carmelitas que são citados como proprietários de fazendas que originaram o bairro do Paracuri, e nessas fazendas, instalaramse as primeiras olarias de Icoaraci com a produção de peças utilitárias. (Tavares apud SOUZA 2010, p. 42).

Vê-se a forte relação entre a criação dessa cerâmica com o seu lugar, ou seja, há na constituição desse sintagma terminológico "Cerâmica Icoaraciense" a ligação com o espaço de confecção, como se expressasse que nascer em Icoaraci, significa ser Icoaraciense. Isso pode ser dimensionado pelo fato desse tipo de prática cultural ter passado por fases, até ser consolidada como a representação, que gera sentido.

\begin{abstract}
A cerâmica icoaraciense era constituída, inicialmente, por reproduções de peças arqueológicas, principalmente das fases Marajoaras, Tapajônicas e com menor intensidade da fase Maracá, vasos com pinturas de decapé e uma mistura dessas duas, variando conforme a criatividade do mestre-artesão. Por volta de 1970 ocorreu o que podemos chamar de apogeu da cerâmica, pois, muitos turistas de todos os lugares do mundo, vinham e encomendavam peças de cerâmica do Bairro do Paracuri, pertencente ao Distrito de Icoaraci, onde a concentração de artesãos era mais forte (FERRETE, 2005, p. 81).
\end{abstract}

O processo histórico, dinamizado pelo aumento da procura dos objetos, as peças em cerâmica que imprimem identificação singular, expressivas desse lugar, chamado Icoaraci, permitem criar o sentido na utilização do termo, para as pessoas que as reconhecem com sua característica única, ou seja, esse tipo de confecção da cerâmica tem a sua relação interligada com o seu lócus de criação, "o Distrito de Icoaraci criou um estilo particular com traçados e formas próprias" (XAVIER, 2010, p. 28), a forma como são grafados os desenhos o torna peculiar, o que permite a criação de sentido e representação, vê-se que essa forma de enunciar distingue o objeto 'cerâmica' e cria vínculo com o local de criação Icoaraci. A partir da apreensão desse conhecimento é possível indicar a constituição do sintagma terminológico: "Cerâmica Icoaraciense". 
Apontar que o termo passa por um processo de apropriação do seu sentido a partir do momento em que o sujeito artesão cria a peça em cerâmica. As pessoas que a reconhecem, artesãos, consumidores, estudiosos, etc., remetem o seu significado ao seu lugar, ou seja, ao plano do espaço físico, dessa criação, havendo uma inter-relação no processo de apropriação do sentido. A definição pode ser vista diante da percepção do discurso assumido pelo sujeito, "o discurso, tornar possível tanto a permanência e a continuidade quanto o deslocamento e a transformação do homem e da realidade natural e social" (ORLANDI, 1999, p. 15) a partir da concepção ideológica sobre a forma de falar sobre o fenômeno, os sujeitos tendem a criar a identidade ao nomeá-lo. Diante do estabelecimento do sentido do termo o objeto está ligado ao local de origem da prática cultural, os sujeitos que fazem uso dos vocábulos em algum momento criaram esse sintagma terminológico.

Dentre as várias formas de expressão, decidiram, mesmo que involuntariamente, fazer essa seleção e a nomearam, "el efecto de esa vida social sobre los signos es precisamente um efecto cultural; es decir, es resultado de um cultivo de los signos, que seleciona sus usos y precisa sus matices para hacer de ellos instrumentos expressivos adecuados a sus necessidades y sus valores" (LARA, 1999, p. 50). A necessidade de indicar os elementos presente na vida cotidiana motiva a criação de novos vocábulos, a interação junto ao espaço social favorece o aparecimento da nova forma de expressão com o objetivo de representar o acontecimento.

O termo "Cerâmica Icoaraciense" possui vínculo com o tipo de produção e com o local de criação e isso designa o efeito de sentido no contexto de uso da prática cultural, esse recurso da língua é fundamental para intitular fenômenos presentes na realidade do repertório linguístico dos usuários. Também podem ser vistos como efeito de valorização da prática cultural com o lugar os sujeitos que a usam quererem a indicar como própria do local, pois, se criada em Icoaraci, possui características específicas. Essas ponderações favorecem reconhecer o valor de identidade dessa prática cultural.

As formas e traços que a caracterizam mantém relação com as diferentes formas de cerâmicas produzidas no lugar ao longo do tempo, visto que os ceramistas/ artesãos faziam peças utilitárias inicialmente e, devido a essa habilidade, foram os primeiros a fazer réplicas da cerâmica Marajoara. "No século XIX, produziam-se em Icoaraci apenas cerâmicas utilitárias, como potes, jarras, panelas e alguidares, mas entre os anos de 1960 e 1970, iniciou-se a disseminação da reprodução das peças arqueológicas Marajoara." (LINHARES, 2011, p. 3), o processo histórico de desenvolvimento da prática cultural no lugar a dimensiona à ação, ou seja, com o passar do tempo à criação das peças foram agregados os valores a partir das influências das cerâmicas de outros tempos e lugares, como a cerâmica Marajoara.

A cerâmica tipicamente icoaraciense é altamente consumida pela população local, nos dias atuais, que junta aos traçados indígenas milenares, os motivos florais estampados em vasos modelados com as formas tradicionais da cerâmica amazônica. Os desenhos retratam o sol, a lua, montanhas, rios e 
outros elementos que o indígena, embora em contato direto com a natureza, jamais reproduziu em seus trabalhos.

No acabamento das peças produzidas, se mantêm as bordas típicas das genuínas peças marajoaras. O resultado final é um híbrido que nada tem a ver, nem com a arte indígena, nem com a cerâmica artística que hoje se produz no país. Para uns, isso representa a descaracterização da cultura original; para outros, enseja o surgimento de uma nova escola de arte cerâmica - a cerâmica icoaraciense. (FERRETE, 2004, p. 5).

A defesa da nova forma de criação artística faz parte da pesquisa de campo realizada em lócus, ao destacar os elementos que caracterizam a prática cultural e esse fato merece destaque, ao refletir a validade do estudo de especialidade sobre o termo, foco essencial do estudo realizado sobre o objeto.

É importante também considerar o processo de ocupação do lugar, o fato de ter sido o lugar de reprodução da cerâmica arqueológica merece destaque, lembrando que inicialmente para fins de pesquisa "As reproduções de Cardoso eram tão bem feitas que, no período mencionado, ele obteve a autorização de pesquisadores do Museu Paraense Emílio Goeldi (MPEG) para ter acesso às peças arqueológicas e reproduzi-las na própria Instituição.” (LINHARES, 2011, p. 3), a ação possibilitou que os artesãos do local entrassem em contato com as formas predominantemente geométricas da arte marajoara, e em consequência, com o passar do tempo, devido à habilidade dos mestres artesãos, ao confeccionar as peças, criou-se uma identidade própria do local, uma nova forma de confeccionar a cerâmica, acrescentado traços, que lembram a arte marajoara ao usar as formas geométricas, porém adicionam imagens: de motivos florais, da lua, do sol, dos igarapés; que fazem lembrar características da amazônica e, com isso, retratam de maneira geral Icoaraci dentro do espaço, já que faz parte da região amazônica.

A cerâmica produzida em Icoaraci sofreu e sofre influência da cerâmica Marajoara devido a fazer parte das peças elementos como os traços geométricos, que lembram a cerâmica arqueológica marajoara. Já, as cerâmicas arqueológicas Tapajônica e Maracá pouco influenciaram nos traços que compõem a cerâmica Icoaraciense, apesar do local continuar fazendo réplicas de ambas.

As peças produzidas em Icoaraci dimensionam a caracterização do lugar, como centro de referência na criação da cerâmica, sendo assim, a constituição do termo "Cerâmica Icoaraciense" justifica uma forma de resistência ao dar o título a partir do elemento produzido, no caso cerâmica, e dar o nome do lugar Icoaraci na sua forma derivacional, em vista de atribuir-lhe a identidade, como centro de criação da prática cultural.

\section{Considerações finais}

A atividade de análise do termo no plano da linguagem cria a possibilidade de compreender o sentido do léxico utilizado por falantes, demarcando a forma como as pessoas do 
lugar e, no caso do foco da abordagem desse estudo, há também a presença dos consumidores, que, ao se comunicarem, demarcam a expressão que identifica a prática cultural. O contexto de uso do termo é uma referência que possui destaque, pois é dentro desse espaço os falantes selecionam os signos linguísticos que caracterizam o objeto estudado, isso justifica a utilização de textos que os especificam nessa análise.

A instituição do sentido parte do princípio dos estudos terminológicos e valida a utilização de textos de especialidades. As pesquisas científicas sobre a "Cerâmica Icoaraciense" favorecem e consideram a importância desses documentos científicos, tanto no plano do estudo da linguística, considerando o fator interdisciplinar dessa análise, como validam as leituras sobre o tema no seu valor amplo e, posteriormente, possibilita fazer o recorte do foco de estudo.

$\mathrm{O}$ entendimento constituído ao longo da investigação cria a possibilidade de compreender o sentido do sintagma terminológico Cerâmica Icoaraciense instituído em três pontos: a) diz respeito à distinção do termo cerâmica: a criação de objetos confeccionada a partir da matéria prima argila, atrelado à maneira como a prática se inter-relaciona e ao modo como os sujeitos que delas usufruem a demarcam; b) delimita que a identificação faz suscitar o termo Icoaraciense faz referência a quem nasceu no distrito industrial de Icoaraci e a cerâmica criada pelo mestre- artesão é feita nesse lugar que faz parte da cidade de Belém, sendo assim, existe um vínculo de início com lugar; e, por último, c) determina que diante da compreensão tem-se o sintagma terminológico: "Cerâmica Icoaraciense", fruto de uma relação de apropriação do sentido, ou seja, a criação da cerâmica está atrelada à produção com o seu lugar, à sua origem, fruto de um processo socio-histórico na Amazônia.

A criação de uma relação de sentido entre as duas palavras e agora um termo que determina o significado da manifestação cultural revela que essa apreensão perpassa pela necessidade que o falante tem de identificar o fenômeno ao nomeá-lo. Para realizar a nominalização do termo foi necessário agregar o valor do tipo de criação com o seu lugar de confecção. A ação dentro do plano do discurso eleito pelo sujeito pode ser entendida como uma forma de resistência e demarcação de lugar, além disso, o uso de sintagma terminológico, de imediato, identifica como de origem do distrito de Icoaraci.

Por fim, é possível concluir que os estudos terminológicos possibilitam ampliar a visão sobre os estudos do léxico da língua, como língua viva e passível a criação de expressões que delimitam a sua variação, pois o falante tem a possibilidade de criar novos léxicos para favorecer a comunicação entre os usuários e possibilitar a validação do termo também como identidade.

\section{REFERÊNCIAS}

AVIZ, Adriana de. As empresas pesqueiras de Icoaraci. Amazônia: Ci \& Desenvol. Revista virtual do Banco da Amazônia Belém, v.2, $\mathrm{n}^{\circ}$ 3, jul./ dez., 2006. Disponibilidade em: 
<http://www.basa.com.br/bancoamazonia2/Revista/edicao_03/Empresas_Pesqueiras_I.pdf>. Acesso em 25 set. 2013.

Dicionário Eletrônico Houaiss da Língua Portuguesa. Versão 1.0.10. RJ: 2006.

FAULSTICH, Enilde. Entre a sincronia e a diacronia: variação terminológica no código e na língua. Actas da VI Riterm, Havana, Cuba, 1998.

FERRETE, Rodrigo Bosi. Investigando a matemática presente na Arte Cerâmica de Icoaraci. In. VIII Encontro Nacional de Matemática. Universidade Federal de Pernambuco. Recife, $2004 . \quad$ p. $112014 . \quad$ Disponibilidade em: <www.sbem.com.br/filles/viii/pdf/05/cc6862794787.pdf>. Acesso em 29 set. 2013.

A etnomatemática da ornamentação da cerâmica icoaraciense praticada no Liceu do Paracuri. 2005. 194 f: Dissertação (Mestrado em Educação) Universidade Federal do Rio Grande do Norte. Centro de Ciências Sociais Aplicadas. Programa de Pós- Graduação, Natal, 2005.

KRIEGER, Maria da Graça; FINATTO, Maria José Bocorny. Introdução à terminologia: teoria e prática. São Paulo: Contexto, 2004.

LARA, Luis Fernando. Termino y cultura: hacia uma teoria del término. In CABRE, M. Teresa. Terminologia e modelos culturales. Barcelona: Institut Universitari de Linguistica Aplicada, 1999.

LINHARES, Anna Maria Alves. De caco a espetáculo: a produção de cerâmica de Cachoeira do Arari (Ilha do Marajó/PA). In. XV Congresso Brasileiro de Sociologia. Curitiba (PR), 2011. p. 1-18. Disponibilidade em: <www.sbsociologia.com.br/portal>. Acesso em 29 set. 2013.

MAINGUENEAU, Dominique. Gênese dos Discursos. São Paulo: Parábola Editorial, 2008.

MICHALISZYN, Mario Sergio; TOMASINI, Ricardo. Pesquisa: Orientações e normas para elaboração de projetos, monografias e artigos científicos. Petrópolis, RJ: Vozes, 2008.

ORLANDI, Eni Puccinelli. Análise de Discurso: Princípios \& Procedimentos. Campinas, SP: Pontes, 1999.

POSSENTI, Sírio. Sobre as noções de sentido e de efeito de sentido. In. POSSENTI, Sírio. Os limites do discurso: ensaios sobre discurso e sujeito. Curitiba-PR: Criar Edições Ltda, 2002.

SOUZA, Doracy Moraes de. O trabalho dos artesãos ceramistas em Icoaraci, Belém/ PA: contribuições aos estudos sobre a dinâmica da Amazônia brasileira. 2010. 122 f. Dissertação (Mestrado em Ciências Sociais) Instituto de Ciências Sociais Aplicados, UFPA, Belém, 2010.

XAVIER, Leandro Pinto. FAZENDO ARTE: a relação entre o valor simbólico e o valor utilitário da cerâmica no Distrito de Icoaraci/ Pa. Belém: Lato\& Sensu, 2001. P. 23-29. Disponível em <www.nead.unama.br/site/bibdigital/pdf/artigos_revistas/51.pdf>. Acesso em: 23 ago. 2013.

\section{Notas:}




\footnotetext{
${ }^{1}$ Artigo resultado da disciplina Terminologia e Tradução, orientado pela Professora Dra . Raimunda Benedita Cristina Caldas, no Programa de Pós- Graduação em Linguagem e Saberes na Amazônia, UFPA- Campus Bragança.
}

[Recebido: 16 nov. 2013 / Aceito: 05 mai. 2014] 